\title{
28 Resarch Square \\ Modeling Of Conceptions Of Health: A New Tool In Health Education
}

Pascal JAVERLIAT ( $\nabla$ pascaljaverliat2815@gmail.com )

Universite Clermont Auvergne Collegium Sciences de la vie Sante Environnement

Frank Pizon

Universite Clermont Auvergne CNRS SIGMA Institut Pascal

Laurent Gerbaud

CHU and Universite Clermont Auvergne CNRS SIGMA Institut Pascal

\section{Research article}

Keywords: andragogy, conceptions in health, education, modeling, osteopathy

Posted Date: March 31st, 2020

DOI: https://doi.org/10.21203/rs.3.rs-17815/v1

License: (a) (i) This work is licensed under a Creative Commons Attribution 4.0 International License. Read Full License 


\section{Abstract}

BACKGROUND: Conceptions allow individuals to interpret reality and to act on it according to their own form of coherence and validity. If a student's conception of health is not organized at the beginning of the course so as to accept that the three domains of the biopsychosocial concept act on an equal footing, it is possible that notions brought by the instructors, relating to a domain that the student considers less operational, are too far removed from his proximal zone of development. This article proposes to shed light on this issue through an analysis, leading to a modeling of students' conception of health at the beginning their osteopathy studies.

METHODS: A semi-directed questionnaire survey was conducted among osteopathy students during their first week of training. The contents of the verbatims were analyzed according to their blocks of meaning, categorized to bring out the different conceptions of health and then modeled using network visualization software to illustrate the links and the relative weight of the different items of conceptions.

RESULTS: We identified 36 categories of conceptions of health. The modeling shows strong links between the psychological and biological domains, while the social domain is isolated.

CONCLUSIONS: From an andragogical perspective, modeling conceptions of health can allow students to situate their life course in relation to health and instructors, in order to identify the components of health conceptions that they do not yet mobilize.

\section{Background}

The initial training of health professionals in France gives pride of place to scientific, and particularly, biomedical disciplines (Official Journal) ${ }^{1,2,3}$. Osteopathy is no exception to the rule since the curriculum reserves about 1,400 hours out of the 4,860 hours of training (Official Journal) ${ }^{4}$ and there is only a total of about 100 hours devoted to public health, psychology and sociology. The biopsychosocial model proposed by Engel (Engel 1977) ${ }^{5}$ is, however, recommended as a conceptual framework for a systemic approach to health. However, the sequencing of training into specific teaching units makes it complex to appropriate the three domains of this model as a coherent whole. Regardless the student's origin - scientific or literary bachelor's degree - or his or her a priori in terms of care and approach to the person, he or she will have to accept, during the first cycle of study, surrendering to the reductionism of biomedical and segmented theoretical knowledge. Thereafter, during the clinical training periods, the osteopathic student will be invited by the instructors to analyze the stabilizing or destabilizing effects that the biological, psychological and social levels of organization have on the health of the patients who consult them.

We have selected osteopathic students for two main reasons. The first is that osteopathy, although part of the vast heterogeneous field of alternative and complementary medicine, maintains a close link and encompasses an understanding with the conventional health care system in France (Suissa 2019) ${ }^{6}$. The frame of reference for training in osteopathy (Official Journal 2014) ${ }^{4}$ plans to address the existence of this bivalence through the study of "the place of empirical processes in medicine" and "a critical and updated 
reading of the principles and foundations of osteopathy with regard to the contribution of science". The second reason is that training in osteopathy is an experiential learning process (Balleux 2000) ${ }^{7}$, proposing numerous teachings and situations, allowing the development of skills that are as close as possible to the reality that the student will have to live through during their professional practice (Mandeville 2004) ${ }^{8}$.

Conceptions allow individuals to interpret reality and to act on it according to their own form of coherence and validity. Conceptions of health develop in childhood (Pizon 2019) ${ }^{10}$. To maintain their operational aspect, they evolve by drawing on knowledge, personal practices and collective experiences. The conceptions of health of individuals undertaking health studies, because of their partly empirical and experiential nature, are unlikely to be homogeneous. The lack of data on this young adult population (Cicchelli 2001) ${ }^{11}$ represents a difficulty for health profession educators when they want to structure their interventions. This prompted us to conduct an exploratory study in this field and to propose a tool that can be used as a lever in terms of learning: network modeling. If a student's conception of health is not organized at the beginning of the course so as to accept that the three domains of the biopsychosocial concept act on an equal footing, it is possible that notions provided by the instructors, relating to a domain that the student considers less operational, are too far removed from his proximal zone of development. In order to support the process of supporting the student and develop "competency that goes beyond what the student would have achieved by his or her own efforts if he or she had remained unaided" (Bruner $2004)^{12}$, instructors need to adapt their discourse. To do this, they need to know the differences among students, to understand the extent to which their conceptions of health do or don't follow from the three domains of the biopsychosocial model. Are there dynamic system links between indicators in these three domains? This article proposes to shed light on this issue through an analysis, leading to a modeling of the conception of health, articulated around the determinants, domains and factors of health evoked by students at the beginning of their osteopathy curriculum, all while using network analysis and visualization software.

\section{Methods}

The study was approved by the Scientific Council of the European Center for Higher Education in Osteopathy. Respondents were recruited from first year students of an osteopathy school in France, on a voluntary basis. We paid attention to gender selection bias, respecting the same proportion of women and men among the respondents as in the promotion (Wang 2013) ${ }^{14}$, (Vlassof 2007) ${ }^{15}$. During the first week of the course, we conducted a semi-directed questionnaire survey. The first question asked was very openended in order to guide the students as little as possible and to be able to glimpse at whether or not his or her conception spontaneously followed from the three domains of the biopsychosocial model: "What does health mean to you?". At the end of this first question, the students were asked whether they thought that "factors influence health" and then, according to their answers, they were asked to specify how each of the factors they had mentioned influenced health.

The contents of the verbatims were analyzed according to their blocks of meaning (Bardin 2001) ${ }^{16}$. The meaning blocks were indexed in order to create different categories. A referencing chronology was applied 
during indexing. The first referencing rank refers to the determinants of health in the Dahlgren and Whitehead model (Dahlgren and Whitehead 2002) ${ }^{17}$. The second rank refers to the domains of the biopsychosocial model. The third and final rank refers to the factors influencing health, mentioned by students. Some verbatims were indexed in several categories. When some content in the verbatims was not explicit enough to be indexed in one category, it was taken out of the stream. An Excel® file was used to create a database of all the meaning blocks.

Our proposal to model students' conception of health is based, in its first stage, on a proven methodology (Pizon 2019) ${ }^{10}$, (Cardot 2010) ${ }^{13}$ that takes the three domains of the biopsychosocial model on "an equal footing, in a system of complex, multiple and circular causalities" (Pizon 2019) ${ }^{10}$. As these studies have shown, each of these domains can be recruited by individuals to develop their conception of health. Depending on the circumstances, this recruitment may be cumulative, resulting in interactions between two or even all three domains. These interactions could be schematized in the form of three interlocking circles, materializing seven sectors, which support seven potential categories making up the conception. (Fig. 1)

While this modeling by interconnected circles indirectly illustrates the existence of links between the constituent categories of the conception, it does not allow the strength of the links between the categories or between the indicators of these categories to emerge. To bring out these conception systems, we propose using network analysis and visualization software. These types of software allow us to visualize the global connectivity of content. Their algorithm is based on graph theory, which produces abstract models of network designs linking objects.

From a general point of view, a graph is a set of pairs, triangles, quadrilaterals, etc., made up of vertices (or nodes) and edges (or lines) connecting these vertices. The edges can indicate the direction of the relationship between the vertices. In this case, they are represented by an arrow. The graph is then said to be oriented or directed. We will only describe the so-called multipolar graph shape, which corresponds to the one taken by the network of our data. Multipolar graphs are characterized by two types of edges; those that form the links emanating from the pole to distinctive nodes and those that form the links emanating from one pole to another pole. Poles can take a structured architecture. We have chosen the centralized structure with respect to the three domains of the biopsychosocial model. Consequently, in the graphs presented below, the more frequently one of these domains will have been cited by students, the more central it will be in the graph. A graph is labelled. Each vertex or edge belongs to a set, and therefore bears a label. A label can belong to any set: color set, word set, object set, etc. The label can be used to identify the set. Our graph will, on the one hand, have colored labels to differentiate the three domains of health (biological, psychological and social), and on the other hand, labels indicating the nature of the nodes. In summary, the typology of our graphs is multipolar, oriented, with double labeling, in order to show the structuring poles of the conceptions, the links between categories and their meaning. (Fig. 2)

We chose the Gephi 9.2 network visualization software because of its free access. The Excel-format database has been changed into "csv" format, so that the three categories constituting the conceptions do not appear in the same column, with semicolons as separators, since the verbatims are written in French (CSV separator: semicolon). We have selected the recommended modeling for small networks called "force 
atlas" (ESIPE 2013) ${ }^{18}$. The "actors" of the network are the matrices items we defined in the previous paragraph. The force atlas modeling algorithm is based on the principle of the forces of attraction or repulsion of the actors composing the network. The actors, represented by nodes in the graphs, are considered attracted to each other when they are associated in a verbatim sequence. The nodes that represent them are then all the closer to each other, the closer the associations are in the verbatim. Conversely, when actors are not associated in verbatim sequences or are distant from each other in verbatim sequences, they are considered to be repulsed. The size of the nodes corresponds to the number of citations in the verbatims. The thickness of the links corresponds to the quantity of associations between items.

So as to not overload the graph and in order to make it more readable, when a triple association matrix [Determinant - Domain - Factor] was first created in the database, the matrices of the same nature found later in the verbatims were replaced by the only one [Factor] that was placed on the same line of the spreadsheet. This in no way changes the links between determinants and domains and between domains and factors, since the entry by the couple [Determinant - Domain] is located in the first two cells of the spreadsheet row. This keeps the determinants off-centered on the graph, centralizes the domains and illustrates the frequency of the links between the domains and the factors. If we had only populated our database with triple association matrices, all determinants and domains would have been centralized. The links between determinants and domains would have overlapped in number and thickness with the links between determinants and factors, making the graph incomprehensible.

We did not carry out frequency measurements or comparisons of the different categories because our sample was only partially representative of the entire promotion.

\section{Results}

25 questionnaires representing $47 \%$ of the students were analyzed, $40 \%$ of whom were male and $60 \%$ female. We identified 36 categories of conceptions of health (Table 1), based on three individual determinants of health (individual characteristics, individual lifestyle habits and behaviors, and individual skills and abilities), four determinants of living environments (physical environment, work environment, family environment and other social networks) and one determinant of the overall environment, which includes social-cultural models, values and norms. Health factors are mainly biological, and in descending order, psychological and social.

Modeling (Figure 3) shows a predominance of linkages that are centered in the biological domain. This domain is strongly related to individual lifestyles and behaviors, characterized by two main health factors: physical activity and food. It is less strongly related to individual characteristics, instead characterized by two main health factors: firstly, the presence or absence of diseases or symptoms, and secondly, the presence or absence of self-regulation. It is also less strongly related to social-cultural patterns, values and norms, characterized mainly by personal standards. Complementary linkages are found in relationships to individual competencies and skills (primarily ability to act), the physical environment and the workplace. The psychological domain is strongly related to individual competencies and skills, mainly the students' 
own emotions and feelings. It is less strongly related to individual characteristics, instead characterized, in the biological domain, by two main health factors: the presence or absence of diseases or symptoms and the presence or absence of self-regulation. It has a complementary relationship with lifestyle habits and individual behavior, with regard to risky behavior and consumption, and the work environment for its toughness. The social domain is the least recruited and appears to be isolated from the other two. It is in mainly connected to different social networks. These may be clearly defined (work, family), but often they are not, hence the need to create "other social networks" category. Relationships do exist, but there are few with the biological domain in their individual characteristics, in terms of purchasing power, and with the psychological domain in their individual skills and abilities, when compared to others.

\section{Discussion}

The choice of semi-directive interviews as a data collection technique allowed us to guarantee all the questions we wanted to address with the students. However, participation in the study was voluntary. It is possible that our sample presents a selection bias and is mainly composed of students corresponding to the profiles of individuals who are spontaneously interested in the approach and/or questioning of their conceptions of health. Nevertheless, we believe that we found sufficient redundancies in the last interviews to estimate that the new data collected would no longer sufficiently contribute to the general understanding of students' conceptions (Savoie-Zajc 1986) ${ }^{19}$. The indexing of verbatim sequences was carried out solely by the principal author. It is therefore subject to a possible bias of appreciation that could have been corrected by a second analysis carried out by another person. However, a second analysis could in turn have introduced an inter-indexer consistency bias (Bertrand-Gastaldy 1986$)^{20}$. Our general hypothesis is that, despite similarities in the meanings of certain French words when taken out of context, there is sufficient contextual orientation of verbatims so that their indexing is not systematically subject to interpretation. In any event, when this occurred, our approach was to remove the verbatim sequences from the indexing stream.

We have highlighted the drafting of eight determinants of health. These are preferably centered on the individual. This suggests that, in terms of health, the perception of reality among these students materializes in situations in which the individual would be dependent on personal characteristics, habits, behaviors, skills or aptitudes. We frequently found sequences of verbatims referring to the "absence of" versus the "presence of" dichotomy: presence/absence of self-regulation, diseases or symptoms, referring to the biological and psychological domains. Although the students were only asked about health, it seems that referring to a model in which illness can also be the expression of health helps to feed the organization of their conception. The three "punitive" models of illness according to Sarradon-Eck (Sarradon-Eck 2002) ${ }^{21}$ are represented: the biomedical model, in which rules, norms or prohibitions are respected or transgressed; the field model, in which it would be the individual's interior that would not be able to maintain the conditions of a state of health, requiring the improvement of his natural defenses or his energies; and the psychosomatic model, in which it would be the individual's personality that would not allow him to solve his adaptation problems, causing him to somatize, thus requiring work on himself. The 
psychological field to which this last punitive model refers to is, for the rest, mainly characterized by references to one's own feelings or emotions.

The biological and psychological domains dominate in the verbatims, returning the social domain to the auxiliary rank of the other two aspects. This first observation seems to concur with some critics of the biopsychosocial model, who claim that it "essentially retains a strong biomedical perspective and fails to effectively involve or include the social" (Chamberlain 2009) ${ }^{22}$. This is not to say that the biopsychosocial model has not been a success. The dichotomy found in these students can be explained, on the one hand, by the fact that the students who enter this school are mostly from a scientific background where the biological model dominates (scientific baccalaureate and first common year of health studies). On the other hand, the orientation towards health studies encompasses a desire to "heal to cure" and its corollary, which is empathy. This ability to perceive the affectivity of the other refers to the psychological domain and seems to play an important part in the organization of their systems of conception.

The social domain is off-center and not very abundant. It refers to two determinants that students clearly identify as the workplace and family. However, the relationships with these two determinants are not the strongest. When the social domain is referred to, it is usually done in vague terms, forcing us to refer to this category - which is less than the two previous ones - as "other social networks" because we could not attribute a more distinctive character to it. Access to health care and the quality of health services, for example, are not mentioned, even though these students are destined for a health profession. Health knowledge is not related to the education system but to individual skills, as well as purchasing power, which would be individual and not social in nature. Students at the beginning of their studies therefore seem to present difficulties in mobilizing the social resources that condition health. Their system of conception of health seems to present, on the one hand, weak links between the social domain, and on the other, the biological and psychological domains. We were able to identify a link via the workplace. When a link is created, it is through individual characteristics, skills and abilities, and not through communitydependent characteristics such as lifestyle, environment or social-cultural models.

The biological domain is abundant. It brings together a large number of health indicators; indicators that could have been even more numerous if we had dissociated references to the "presence" and "absence" of the same factor. The central positions of the "individual lifestyle and behavior" determinant and the "biological domain", as well as the strength of the link between them, illustrate the dominant student perspective of health. Health consists of eating well, having an adapted physical activity, avoiding risky behaviors and consumption, having a good sleep rhythm, carrying out care, treatment and prevention. This vision of health is complemented by individual characteristics, mainly the presence or absence of selfregulation, which refers to knowledge of physiology that is being developed, and the presence or absence of disease or symptoms. Given the study population, we assumed that the concepts of environment and/or environmental risk would be prominent (Abdmouleh 2011) ${ }^{23}$. While pollution, pesticides and endocrine disruptors have sometimes been cited, we find that these health factors are only related to the biological domain. The determinant of individual characteristics is more eccentric than that of lifestyle habits and individual behaviors because it is also related to the psychological domain. The presence or absence of 
self-regulation and the presence of diseases or symptoms refer to both domains. Modeling has shown the specificity of a strong link between the psychological domain and one's own feelings and emotions. Since this factor is not related to any other determinant or domain, it occupies an eccentric position, but the strength of the link is very real. It appears thanks to a heavy link, comparable to the strong links already mentioned such as the links between the biological and the presence or absence of self-regulation or physical activity.

\section{Conclusions}

Modeling appears to be a tool for visualizing the health conception systems of early-stage students. The conception of health surveyed among students essentially mobilize the individual determinants of health. The three domains of the biopsychosocial model are combined with varying degrees of participation and association. The modeling shows strong links between the psychological and biological domains, while the social domain is isolated. Our situation, as a researcher in a transdisciplinary health intervention evaluation unit, has led us to reflect on the possibility of using modeling as a lever for health pedagogy or andragogy. Modeling, through its ability to visualize organizations in a system, to make their components, links, and greater or lesser strength perceptible, allows students to recognize themselves individually and to see the variety of possibilities in other students in the class. Modeling can allow the student to situate his or her life path in relation to health, to situate himself or herself in relation to the group, while reducing the pitfall often encountered when one has to verbally confront his or her intimate experiences with those of other individuals.

For the instructor in the health profession, modeling seems to be a tool that enables him to appreciate the students' conceptions, of which he knows little a priori, and thus to propose training sequences whose content remains close to the students' proximal development zone. It is a question of creating a dynamic of change that does not overly destabilize the student, so as not to discourage him from evolving.

\section{Abbreviations}

- CNRS : Centre national de la recherche scientifique(National Centre for Scientific Research)

- SIGMA : école d'ingénieur de Clermont-Ferrand (engineering school of Clermont-Ferrand)

- $\mathrm{CHU}$ : centre hospitalier universitaire (university center hospital)

\section{Declarations}

Ethics approval and consent to participate: the study has been approved by the Scientific Council of the Centre Européen d'Enseignement Supérieur de l'Ostéopathie, 175 Boulevard Anatole France, 93200 SaintDenis. France, within the framework of the French law n ${ }^{\circ}$ 2012-300 of March 5, 2012 relating to research involving the human person in France.

(https://www.legifrance.gouv.fr/affichTexte.do?cidTexte=JORFTEXT000025441587\&categorieLien=id) and its decree $n^{\circ}$ 2016-1537 of November 16, 2016. 
(https://www.legifrance.gouv.fr/affichTexte.do?cidTexte=JORFTEXT000033394083\&categorieLien=id) . All students were offered the opportunity to participate in the study. Students were free to accept or decline to participate; their choice did not affect their relationship with the institution or their future studies. Informed consent was attached to each questionnaire. No nominative list was created.

Consent for publication: Consent for future publication was offered to all students, who retain all their rights under the law. Students agreed their personal data will be computorised by the author, for the purposes of study and publication, in accordance with the French law. "computing and freedom - article 40 "

(https://www.legifrance.gouv.fr/affichTexte.do?cidTexte=JORFTEXT000000886460)

Availability of data and material : the datasets used and/or analysed during the current study are available from the corresponding author on reasonable request.

Competing interests: PJ declares invitations as a teacher for the Centre Européen d'Enseignement Supérieur de l'Ostéopathie, 175 Boulevard Anatole France, 93200 Saint-Denis. France LP and LG declare that they have no competing interests.

Funding: the Centre Européen d’Enseignement Supérieur de l’Ostéopathie declares a role in editing the questionnaires only.

Authors' contributions : PJ analyzed, interpreted the students data and wrote. the manuscript. FP and LG reviewed the manuscript. All authors approved the final manuscript.

Acknowledgements: We would like to thank the management of the the Centre Européen d'Enseignement Supérieur de l'Ostéopathie that supports our approach and the students who participated in this study.

\section{References}

1. Université Paris-Est. Algorithmes de modélisation de graphes. https://lipn.univparis13.fr/ toulouse/doc/SupGalilee_INFO/Cours_Algo_Graphes.pdf

2. Dahlgren, G., Whitehead, M. The Dahlgren and Whitehead model in The Future of the Public's Health in the 21st Century. 2002. National Academy Press (US). NCBI Bookshelf. A service of the National Library of Medicine, National Institutes of Health.

3. Bardin, L. L'analyse du contenu. 2013. Presse Universitaire de France. Paris. ISBN 978-2-13-062790-6.

4. Vlassoff, C. Gender differences in determinants and consequences of health and illness. J Health Popul Nutr. 2007 Mar; 25(1): 47-61.https://www.ncbi.nlm.nih.gov/pmc/articles/PMC3013263/

5. Wang, Y., Hunt, K., Nazareth I, and al. Do men consult less than women? An analysis of routinely collected UK general practice data. BMJ Open 2013;3:e003320. http://dx.doi.org/10.1136/bmjopen2013-003320 
6. Cardot, J.P. La formation des enseignants en éducation à la santé : quels déterminants pour les pratiques des formateurs. Actes du congrès de l'Actualité de la recherche en éducation et en formation (AREF), Université de Genève, septembre 2010.

https://plone.unige.ch/aref2010/Livret\%20des\%20resumes\%20AREF2010.pdf

7. Bruner, J. Savoir-faire, savoir-dire. Paris, Presse Universitaire de France. 2004, p 263. ISBN-10 :2130589685

8. Cicchelli, V. Les jeunes adultes comme objet théorique. In: Recherches et Prévisions, n65, 2001. Jeunes adultes. pp. 5-18. https://doi.org/10.3406/caf.2001.961

9. Pizon, F. Health Education and Prevention, Vol. 1. Editions ISTE. April 2019. ISBN : 9781786304100

10. Javerliat, P., Pizon, F. \& Gerbaud, L. Étude exploratoire de la santé musculosquelettique du rachis d'étudiants en ostéopathie. Revue d'Épidémiologie et de Santé Publique. 2020. Disponible sur : https://doi.org/10.1016/j.respe.2019.11.019

11. Mandeville, L. (2004).Apprendre autrement, Pourquoi et comment. Sainte-Foy, Québec: Presses de I'Université du Québec. Pages 70 à 87. ISBN : 2-7605-1281-9.

12. Balleux, A. (2000). Évolution de la notion d'apprentissage expérientiel en éducation des adultes: vingtcinq ans de recherche.Revue des sciences de l'éducation, 26(2), 263-286. https://doi:10.7202/000123ar

13. Suissa, V., Guérin, S. \& Denormandie, P. Médecines complémentaires et alternatives. Pour ou contre? Édition Michalon Paris 2019. ISBN: 9782841869299.

14. Engel, G.L. The need for a new medical model: a challenge for biomedicine. Science 1977;196:129-36. https://doi.org/10.1126/science. 847460

15. République Française. Arrêté du12 décembre 2014 relatif à la formation en ostéopathie ; annexes I \& III. . Published on 12/14/2014. Available from : https://www.legifrance.gouv.fr/affichTexte.do? cidTexte=JORFTEXT000029894219\&categorieLien=id

16. République Française. Arrêté du2 septembre 2015 relatif au diplôme d'Etat de masseurkinésithérapeute; Annexe IV référentiel de formation et unités d'enseignement. Published on 09/04/2015. Available from : https://www.legifrance.gouv.fr/affichTexte.do? cidTexte=JORFTEXT000031127778\&categorieLien=id

17. République Française. Arrêté du 31 juillet 2009 relatif au diplôme d'Etat d'infirmier. Published on 07/31/2009. Available from : https://www.legifrance.gouv.fr/affichTexte.do? cidTexte=JORFTEXT000020961044.

18. République Française. Journal Officiel - Ministère de la santé. Bulletin officiel $n^{\circ} 45$ du 3 décembre 2009. Première année commune aux études de santé. Published on 12/03//2009. Available from : https://www.education.gouv.fr/cid49834/esrs0925329a.html.

19. Savoie-Zajc, L. (1996). Saturation. Dans A. Mucchielli (Dir.) : Dictionnaire des méthodes qualitatives en sciences humaines et sociales.Paris, France : Armand Colin. https://journals.openedition.org/communicationorganisation/1901 
20. Bertrand-Gastaldy, S. Documentation et bibliothèques. 1986. Volume 32,1-2, p. 3-23. Doi : https://id.erudit.org/iderudit/1052706ar

21. Sarradon-Eck, A. (2002). Les représentations populaires de la maladie et de ses causes. Rev Prat Med Gen $2002 ; 16$ (566) : 358-63.

https://www.academia.edu/641489/Les_représentations_populaires_de_la_maladie_et_de_ses_causes

22. Chamberlain, K. Situer le social dans la psychologie de la santé : réflexions critiques. Les cahiers internationaux de la psychologie sociale. 2009-82, p. 7 à 24. https://doi.org/10.3917/cips.082.0007

23. Abdmouleh, L. La conscience écologique citoyenne: de la sensibilisation à la participation des actions écophiles», Les cahiers de psychologie politique. 2011.

http://lodel.irevues.inist.fr/cahierspsychologiepolitique/index.php?id=1874

24. Bouffetal, H., Hermas, S., Noun, M. \& Samouh, N. L’andragogie médicale. Journal de Gynécologie Obstétrique et Biologie de la Reproduction. 2009.Volume 38-5, 445-447. 1016/j.jgyn.2009.04.002

\section{Tables}

Table 1 Health conceptions of students 


\begin{tabular}{|c|c|c|}
\hline Determinants of health & Domains of health & Factors of health \\
\hline \multirow[t]{7}{*}{ Individual characteristics } & \multirow[t]{4}{*}{ Biological } & The presence or absence of self-regulation \\
\hline & & The presence or absence of diseases or symptoms \\
\hline & & The life trajectory \\
\hline & & The body weight \\
\hline & \multirow[t]{2}{*}{ Psychological } & The presence or absence of self-regulation \\
\hline & & The presence or absence of diseases or symptoms \\
\hline & Social & The purchasing power \\
\hline \multirow[t]{10}{*}{ Lifestyle habits and individual behaviors } & \multirow[t]{8}{*}{ Biological } & The physical activity or lack of physical activity \\
\hline & & The food \\
\hline & & The presence or absence of self-regulation \\
\hline & & The prevention \\
\hline & & The sleep \\
\hline & & The risk behaviors \\
\hline & & The consumption at risk \\
\hline & & The cares and treatments \\
\hline & \multirow[t]{2}{*}{ Psychological } & The risk behaviors \\
\hline & & The consummations at risk \\
\hline \multirow[t]{5}{*}{ Individual skills and abilities } & Biological & The ability to act \\
\hline & Psychological & Own feelings or emotions \\
\hline & \multirow[t]{3}{*}{ Social } & The comparison to others \\
\hline & & The health literacy \\
\hline & & The sleep \\
\hline \multirow[t]{3}{*}{ Physical environment } & \multirow[t]{3}{*}{ Biological } & The endocrine disruptors \\
\hline & & The pesticides \\
\hline & & The pollution \\
\hline \multirow[t]{4}{*}{ Workplace } & Biological & The drudgery of the job \\
\hline & Psychological & The drudgery of work \\
\hline & \multirow[t]{2}{*}{ Social } & The influence of others on you \\
\hline & & \\
\hline
\end{tabular}

Page 12/15 


\begin{tabular}{|c|c|l|}
\multirow{2}{*}{} & & The sleep \\
\cline { 3 - 3 } & & The trajectory of life \\
\hline Family environment & Social & The influence of others on you \\
\hline Other social networks & Social & The influence of others on you \\
\hline \multirow{2}{*}{ Socio-cultural models, values and standards } & \multirow{2}{*}{ Biological } & Historical-empirical concepts \\
\cline { 3 - 4 } & & Biomedical standards \\
\cline { 3 - 4 } & & Personal standards \\
\cline { 3 - 4 } & & Advances in science and technology \\
\cline { 3 - 4 } & &
\end{tabular}

the 36 categories of health determinant-domain-factor associations constituting the health conceptions of students entering osteopathy studies. (Saint Denis [France], European Center for Higher Education in Osteopathy, 2020)

Figures

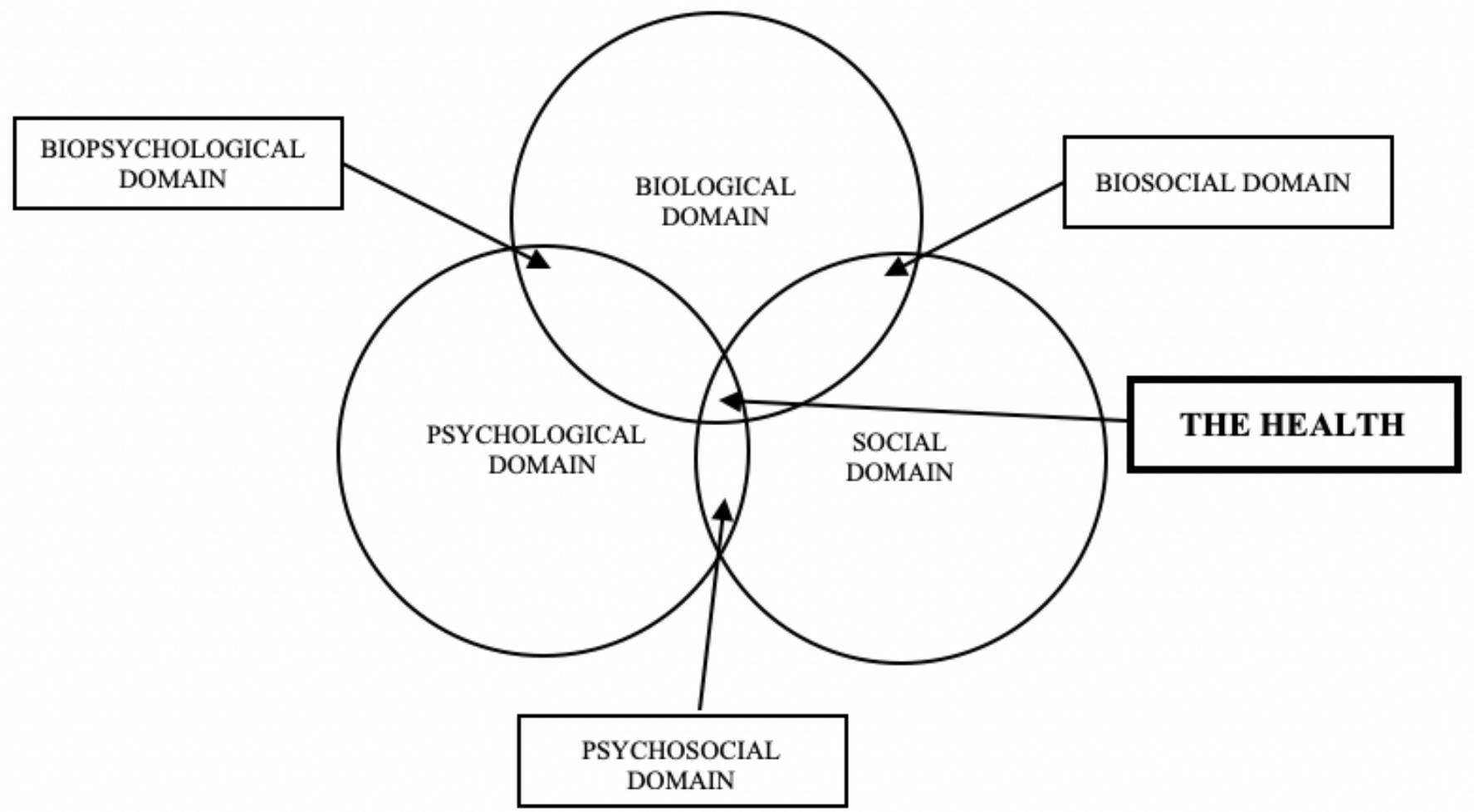

\section{Figure 1}

Schematization of the biopsychosocial model of health. The interactions between the biological, psychological and social domains, interacting on an equal footing in a system of possible health 


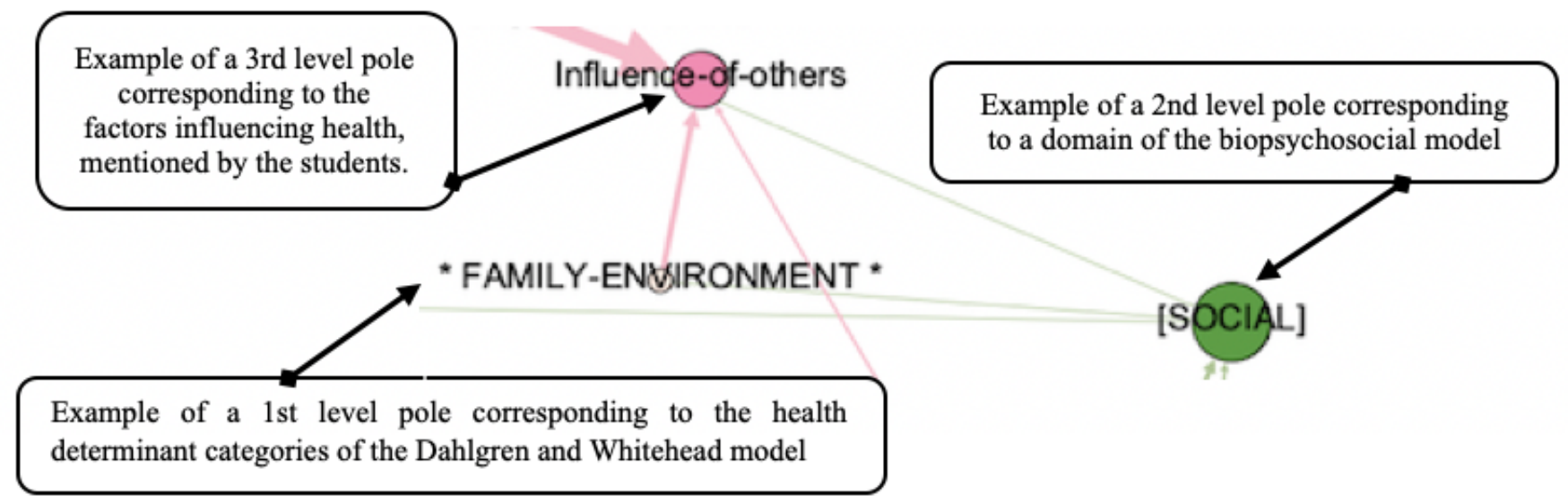

\section{Figure 2}

Modeling of student conceptions of health. Portion of the modeling of student conceptions of health in the form of a multipolar, oriented, double-tagged graph.(Saint Denis [France], Centre Européen d'Enseignement Supérieur de l'Ostéopathie, 2020)

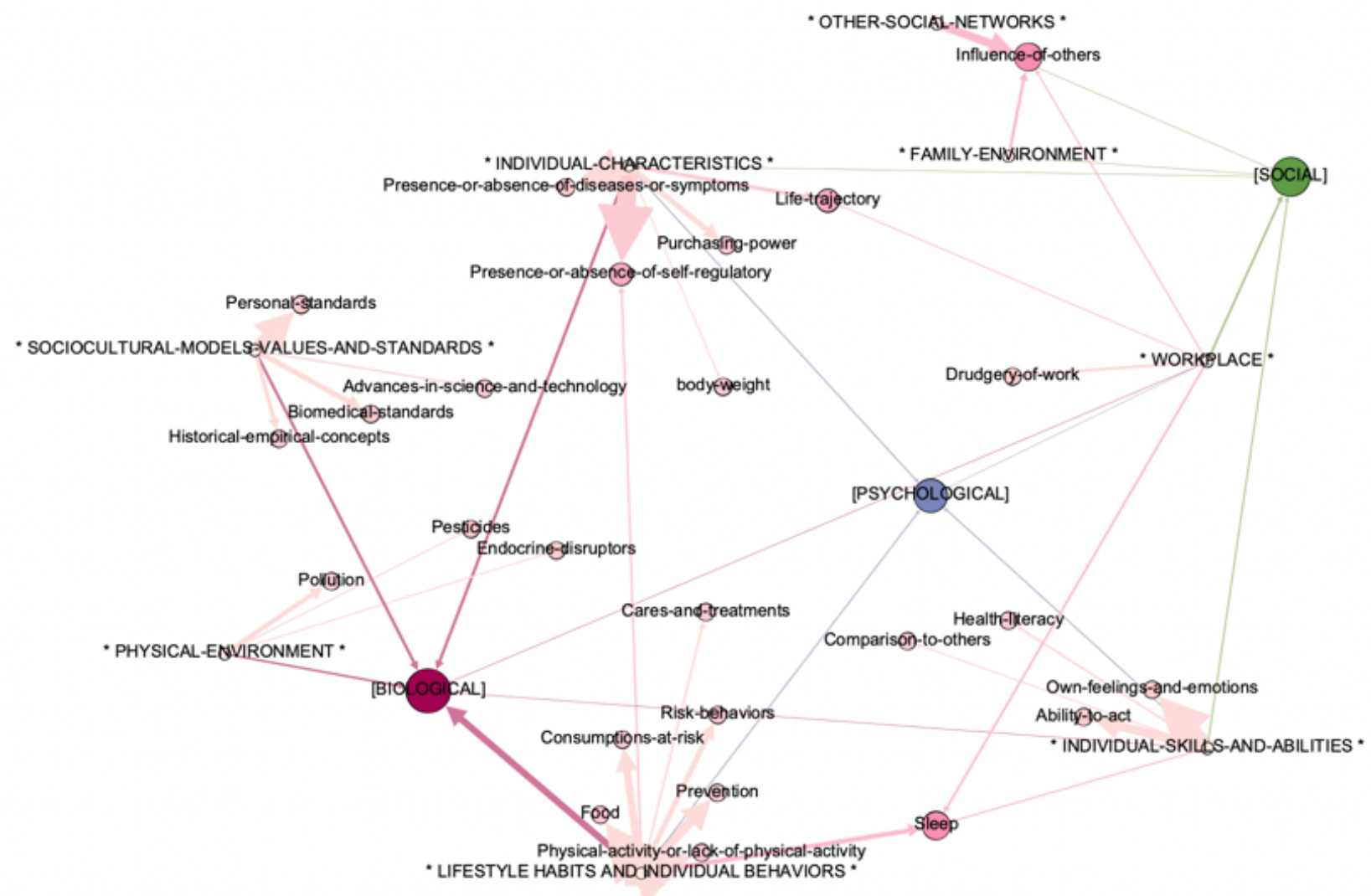




\section{Figure 3}

Graph of the students' conception of health. Modeling shows a predominance of linkages that are centered in the biological domain. The social domain is the least recruited and appears to be isolated from biological and psychological domains (Saint Denis [France], Centre Européen d'Enseignement Supérieur de l'Ostéopathie, 2020) 